\title{
El cubrimiento mediático de los acuerdos de paz en Colombia al inicio de la era de Iván Duque. Entre el pesimismo y la negatividad
}

\section{Carlos Andrés Charry Joya ${ }^{1}$, Diego García Ramírez ${ }^{2}$ y German Ortiz Leiva ${ }^{3}$}

Resumen: El objetivo del presente artículo es analizar la manera como algunos de los principales medios de comunicación colombianos han abordado el tema del proceso de paz y la implementación de los acuerdos logrados con la extinta guerrilla de

\footnotetext{
1 Profesor de Carrera de la Universidad del Rosario. Programa de Sociología. Director de la Maestría en Estudios Sociales. Grupo de Investigación en Ética Aplicada, Trabajo y Cambio Social. Investigador del Observatorio del Conflicto Social.

E-mail: carlosa.charry@urosario.edu.co

Orcid: https://orcid.org/0000-0002-2686-7716.

GS: https://scholar.google.com/citations?user=oGrOtMcAAAAJ\&hl=es.

2 Profesor de Carrera de la Universidad del Rosario. Programa de Periodismo y Opinión Publica. Grupo de Investigación en Ética Aplicada, Trabajo y Cambio Social.

E-mail: diegoalo.garcia@urosario.edu.co

Orcid: https://orcid.org/0000-0002-6173-8047.

GS: https://scholar.google.es/citations? user=rY5BvagAAAAJ\&hl=es.

3 Profesor de Carrera de la Universidad del Rosario. Programa de Periodismo y Opinión Publica. Grupo de Investigación en Ética Aplicada, Trabajo y Cambio Social.

E-Mail: german.ortiz@urosario.edu.co.

Orcid: http://orcid.org/0000-0001-8208-3169.

GS: https://scholar.google.com/citations?user=HFzozuwAAAAI\&hl=es.
}

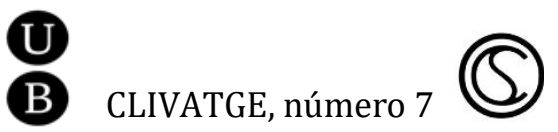


las FARC. En la primera sección, se hace un abordaje del sentido informativo de la noticia como marco conceptual general que permite identificar sus dimensiones y características. En la segunda, se aborda el clima de opinión que se ha configurado en Colombia tras la toma de posesión del presidente Iván Duque. Por último, en la tercera sección, a partir de una perspectiva fundamentada en los métodos mixtos, se analizan las principales tendencias informativas reproducidas por los medios de comunicación sobre el proceso de paz y la implementación de los acuerdos durante los primeros meses del nuevo Gobierno. El artículo termina con unas conclusiones, en las que se presentan algunas de las posibles consecuencias de las malas noticias en los procesos de formación de opinión pública en Colombia en la actualidad.

Palabras clave: acuerdos de paz; medios de comunicación; periodismo; malas noticias; Colombia; métodos mixtos

Resum: L'objectiu del present article és analitzar la manera en què alguns dels principals mitjans de comunicació colombians han abordat el tema del procés de pau i la implementació dels acords assolits amb l'extinta guerrilla de les FARC. En la primera secció, es tracta del sentit informatiu de la notícia, com a marc conceptual general que permet identificar les seves dimensions i característiques. En la segona, s'aborda el clima d'opinió que s'ha configurat a Colòmbia després de la presa de possessió del president Iván Duque. Per últim, a la tercera secció, a partir d'una perspectiva fonamentada en els 
mètodes mixtos, s'analitzen les principals tendències informatives reproduïdes pels mitjans de comunicació sobre el procés de pau i la implementació dels acords durant els primers mesos del nou govern. L'article finalitza amb unes conclusions, on es presenten algunes de les possibles conseqüències de les males notícies en els processos de formació d'opinió pública a Colòmbia en l'actualitat.

Paraules clau: acords de pau; mitjans de comunicació; periodisme; males notícies; Colòmbia; mètodes mixtos

\begin{abstract}
The objective of this article is to analyze the way in which some of the main Colombian media have addressed the issue of the peace process and the implementation of the agreements reached with the extinct FARC guerrilla. The first section deals with the informative dimension of news, as a general conceptual framework that allows identifying its dimensions and characteristics. In the second section, the climate of opinion that has been created in Colombia after the taking-up of President Iván Duque is addressed. Finally, in the third section, and from a perspective based on mixed methods, we analyze the main information trends reproduced by the Colombian media with respect to the peace process and the implementation of the agreements during the first months of the new government. The article ends with some conclusions, which present some of the possible consequences of bad news in public opinion processes in Colombia today.
\end{abstract}

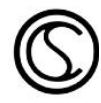


Keywords: peace agreements; media; journalism; bad news; Colombia; mixed methods.

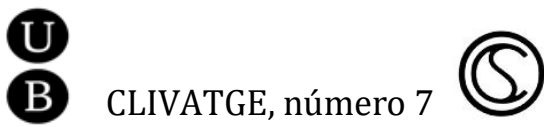




\section{Introducción}

Una noticia es en esencia un hecho contado o narrado sin rodeos; hace parte de un evento histórico de relevancia e interés ciudadano, que relata lo insólito, o bien, referencia una catástrofe o involucra acontecimientos o personas prestantes del arte, el poder o las letras. Eran esas las conclusiones del primer trabajo académico sobre periodismo presentado en la Universidad de Leipzig (Alemania) en 1690 por un erudito de la época de nombre Tobías Peucer (Silva, 2005).

Y aunque desde entonces ha sido así, no hace más de un siglo que la prensa en general, y ciertos sectores de opinión en particular, han debatido sobre la conveniencia o no de narrar historias que se cubren de manera similar en los periódicos, con la presencia de múltiples fuentes informativas interesadas en evidenciar las perspectivas sobre lo que se configura como el hecho noticioso, ante el cual la mayoría de los periodistas parecen estar de acuerdo al tratar de comprender la realidad física y social que acontece (Tranquina, 2008).

El ejercicio de informar de manera periodística terminó por configurarse con los años, en una carrera -en ocasiones desenfrenada- dispuesta a superar los obstáculos propios que permiten sobrevivir a la noticia, trascendiendo la diversidad de "versiones" que se generan en el camino, para constituirse en la más llamativa, verosímil y, por supuesto, cierta. Sin embargo, aquellas historias que resultan disonantes terminarán por ser consideradas igualmente como hechos interesantes, siempre y cuando se use la 
estrategia cínica de la cobertura periodística, que se centra en la denominada "carrera de caballos" y en los aspectos conflictivos de la política que siempre terminarán por captar la atención de los ciudadanos. ${ }^{4}$

En la Colombia del siglo XXI, luego de la firma de un acuerdo de paz con la guerrilla más antigua del hemisferio occidental y la posterior llegada de un partido de gobierno que ha sido un fuerte crítico de los acuerdos logrados, se ha configurado una fuerte controversia pública que genera a diario una enorme cantidad de información de carácter noticioso, la cual hace referencia al denominado "pos-acuerdo". El proceso ha estado signado por la confrontación política por la Justicia Especial para la Paz (JEP), un tribunal de justicia transicional creado para juzgar los delitos cometidos dentro del conflicto armado. A ello se suman los pronunciamientos de líderes de opinión en torno a las dudas y las consecuencias que deja la implementación de la justicia especial de paz, la reparación de las víctimas y el castigo a los culpables de

\footnotetext{
${ }^{4}$ Se toma la definición de cobertura de estrategia de Capella y Jamieson (1997): “(1) ganadora siempre antes que perder lectores como la preocupación central; (2) basada en el uso del lenguaje de las guerras, los juegos y la competencia; (3) relacionada con artistas, críticos y escépticos o público en procesos de decisión; (4) centrada en los resultados del eventual candidato ganador en el campo de lo político; (5) dando gran peso a las encuestas. De este modo, incluye tanto el esquema de "juego" de poderes como la cobertura de una verdadera "carrera de caballos", que a menudo se vuelve confusa hasta el final de la misma (Trussler y Soroka, 2013).
} 
múltiples actos, constituyéndose un escenario que determinados sectores políticos califican como de impunidad.

Es de suponer que el periodismo y los periodistas atiendan con mayor atención las noticias sobre estos asuntos porque, además del interés público que despiertan, conllevan elementos para la legitimación social y el reconocimiento público del hecho político que, por décadas, ha sido considerado como el más relevante del país: el conflicto armado.

Por supuesto, el inmediatismo seguirá reinando en las salas de redacción y la novedad marcará la producción y la difusión de las noticias. Son éstos algunos de los valores-noticia que no han cambiado ostensiblemente desde que Peucer los encontró y definió hace más de cuatro siglos. Su modelo de comprensión de la noticia nos lleva a identificar diferentes criterios de lo que es noticiable, entre los que se encuentran el origen de los hechos y el tratamiento y la priorización de los mismos, en donde intervienen los valores-noticia de los hechos escogidos, así como la manera en que estos están organizados y el formato en el que son reproducidos (Silva, 2005).

Y si bien no se trata de hacer a un lado los parámetros informativos, lo cierto es que, como rasgo distintivo que define su sentido profesional, las noticias encierran todo lo que son los periodistas: personas de acción, marcadas incesantemente por la producción de contenidos, con una mirada inmediatista y de corto plazo de la realidad, que los lleva a seleccionar unos eventos y descartar otros para informarlos apresuradamente a la sociedad, en medio de un tipo de ritual recurrente en el que se seleccionan los 
eventos, se indaga la novedad de las propuestas y se evalúa el número y la calidad de las fuentes informativas.

Sin embargo, en medio de la autonomía para hacerlo y los derechos constitucionales que cobijan a los medios de información y comunicación, ante la compleja realidad colombiana se hace necesario repensar las maneras como se está llevando a cabo la cobertura de hechos tan importantes para el país como lo son el proceso de paz y la implementación de los acuerdos que de él se derivaron, partiendo del criterio de que existen unas metas editoriales que no se deben perder de vista, y la necesidad de una constante autorregulación profesional en aras de mejorar los niveles de información periodística con espacios de credibilidad informativa.

De esta manera, el objetivo del presente artículo es hacer un análisis de la manera como algunos de los principales medios de comunicación colombianos han abordado el tema del proceso de paz, el cual puede dar cuenta de la percepción que las personas tienen de la situación del país y de la implementación de los acuerdos de paz. Para el desarrollo de este objetivo, el artículo se divide en tres grandes secciones. En la primera, se hace un abordaje del sentido informativo de la noticia como marco conceptual general que permite identificar sus dimensiones y sus características. En la segunda, se aborda el clima de opinión que se ha configurado en Colombia tras la toma de posesión del presidente Iván Duque, para luego decantar en una tercera sección, en donde se analizan las principales tendencias informativas reproducidas por los medios de comunicación sobre el proceso de paz y la implementación de los acuerdos durante los

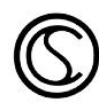


primeros meses del nuevo Gobierno, ejercicio en el cual se presentan y discuten los principales resultados que provee esta investigación. El artículo termina con unas conclusiones generales sobre el caso de estudio analizado.

\section{El sentido informativo}

Tratar de comprender el porqué de las noticias, como el hecho más característico de la tarea del reportero, nos traslada a un escenario conceptual del campo informativo que demarca tres elementos, los cuales, previstos simultáneamente, proyectan algunas de las razones de por qué las noticias son como son.

El primero de estos elementos está asociado con su historicidad. La noticia ha sido desde la aparición del hecho noticioso - un saber propio de quienes así lo consideran - la cualidad que acentúa la experiencia del reportero, no sólo como herramienta de trabajo, sino como criterio que configura lo real, los entornos sociales y la experiencia individual y de conocimiento, como puntos de partida para una práctica profesionalizante que luego del siglo XIX creció paralela a la consolidación del capitalismo y las democracias modernas (Aguiar, 2014).

El segundo hace referencia a su profesionalidad, ciertamente como razón suficiente para adoptar en el interior de las empresas informativas una forma especial de organización ocupacional basada en un cuerpo de conocimiento sistemático - los denominados criterios noticiables - adquiridos con la experiencia de las salas de redacción y a través del cual determinados intereses se van haciendo 
comunes y terminan siendo transmitidos de generación en generación entre los que se dedican a esta actividad.

El tercero está relacionado con su transitoriedad, al ser esta en sí misma una dinámica de comunicación de hechos que acontecen en torno a realidades sociales y físicas en transformación, en donde aparecen a la vez procesos de cambio lentos y acaso evolutivos, así como puntos de quiebra históricos, esto según se presente la coyuntura que los convierte en hechos de carácter relevante, cargados de un sentido real de cambio y novedad (Rosenau, 1997).

Entendidos así, estos tres pilares constitutivos aclaran un poco más las distintas dimensiones de la noticiabilidad, es decir, aquellos parámetros establecidos para lograr que los acontecimientos se transformen en noticias que merecen ser difundidas por los medios de comunicación. ${ }^{5}$

No obstante, uno de los criterios predominantes en la elaboración de las noticias es el de la negatividad. Varias son las causas que lo predisponen; la primera se refiere a la ambivalencia que, como anotábamos antes, suele acompañar a la difusión de los eventos noticiosos en una especie de "carrera de caballos", en la que

${ }^{5}$ Algunos de estos fueron estudiados sistemáticamente desde mediados de los años sesenta. En particular, es de resaltar el trabajo de Galtung y Ruge al referirse a los eventos noticiosos a partir de: (i) frecuencia, (ii) amplitud, (iii) claridad o falta de ambigüedad, (iv) relevancia, (v) conformidad, (vi) imprevisión, (vii) continuidad, (viii) referencia a personas y naciones de élite, (ix) composición, (x) personificación y (xi) negativismo (Galtung y Ruge, 1965). 
generalmente nadie sabe con certeza qué va a pasar. Esta ambivalencia permite contraponer las versiones de las fuentes en un permanente contra-pulso, el cual se hace más evidente cuando se entiende que los medios de información suelen fijar más su atención al elaborar las agendas informativas en aquellos hechos socialmente controvertibles. La ambivalencia fácilmente pasa a ser "ambitendencia" en los consumidores de noticias, fenómeno que se entendió hace más de un siglo desde la psicología y la consolidación del término esquizofrenia por Eugene Bleuler, en 1911, al estudiar el origen de ciertas enfermedades psiquiátricas en su ensayo Dementia Praecox or the Group of Schizophrenias. De este modo, existe una relación con los sentimientos que solemos expresar ante una misma idea que, por sus propias características, pueden presentar "tonalidades afectivas contrastantes" y hacer tener el mismo pensamiento en modo positivo y negativo a la vez (Galimberti, 2002).

Así, lo que es noticiable se encuentra altamente ligado por el denominado sesgo de negatividad, que suele delimitar la pauta de las noticias al resaltar los aspectos en los que las personas ponen mayor atención, dando más peso informativo a lo dramático, lo chocante, la curiosidad mórbida o repugnante por los eventos dolorosos y violentos que describen, hechos que por lo general son los que atraen la atención de los consumidores mediáticos y que suelen volverse virales en las redes sociales. Se trata de un proceso psicológico en el que las notas negativas, las llamadas "malas noticias", siempre serán noticia, lo cual recuerda el viejo aforismo del periodista norteamericano John B. Bogart, quien en 1890 acuño la frase "si un

B CLIVATGE, número 7

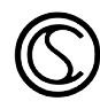


perro muerde a un hombre, no es noticia, si un hombre muerde a un perro, sí", idea que ha estado presente por décadas en el trabajo que realizan directores, editores y reporteros de medios de comunicación.

Los estímulos negativos que demandan las malas noticias son más llamativos y dominantes, y las respuestas a las potenciales amenazas que describen suelen ser más rápidas y fuertes que aquellas que denotan positividad y bienestar. Siempre nos será más fácil recordar las malas experiencias que aquellas escenas en las que nos sentimos más cómodos y seguros.

Esto conlleva implicaciones no sólo para los ciudadanos que, ante el torrente de las noticias malas, suele sobredimensionar aquellos hechos que parecen indicar precisamente que algo malo está a punto de suceder, sino que afecta a la percepción que los reporteros y editores tienen del entorno, el cual perciben agresivo y desafiante. Todo ello termina tensionando de manera constante en su labor de informar desde las salas de redacción, llegando a considerar que el mundo que describen está al borde del colapso, en medio de una conspiración permanente de poderes (Trussler y Soroka, 2013).

Este signo de negatividad ha sido una de las características más recurrentes de la cultura política colombiana, tal y como lo ha señalado en diversas partes el sociólogo francés Daniel Pecaut, quien en una entrevista al periódico El Espectador señalaba que:

Siempre me ha parecido que en Colombia hay mucha dificultad de los mismos colombianos para pensar que el país cambiaba; es decir, no ven sino todo lo negativo, convencidos de que viven en un país condenado al fracaso. Es una concepción mítica del 
tiempo, como la de García Márquez, siempre acontece lo mismo. A veces surge otra mirada, pero siempre una mirada hacia atrás. ${ }^{6}$

Sin embargo, los sesgos informativos asociados a la ambigüedad, la negatividad y el pesimismo se han hecho más evidentes en la prensa colombiana desde el periodo posterior a la firma de los acuerdos de paz de 2016 y durante toda la campaña presidencial del año siguiente, que llevó al poder al candidato del partido opositor a los acuerdos alcanzados con la extinta guerrilla de las FARC, ${ }^{7}$ siendo estos elementos una antesala para comprender la manera como los medios de comunicación han abordado el tema de la paz y la implementación de los acuerdos frente a la realidad política de la que tenían que informar.

6 Para la entrevista completa, véase: https://www.elespectador.com/noticias/nacional/los-colombianosviven-convencidos-de-que-su-pais-esta-condenado-al-fracaso-danielpecaut-articulo-747138.

${ }^{7}$ Este negativismo quedó registrado a comienzos de febrero de 2018 en una de las ediciones de la revista con mayor impacto periodístico, dedicada desde su portada al miedo por la oleada de inseguridad y pánico que, según dicha publicación, padecían todos los colombianos, a pesar del optimismo que se esperaba con un proceso de paz en consolidación. Al respecto, véase: "Miedo. La oleada de inseguridad de los últimos días tiene en pánico a muchos colombianos. Qué tan grave es y qué tan responsables son la falta de justicia y de autoridad", Revista Semana, no 1866, 4-11 de febrero de 2018.

B CLIVATGE, número 7

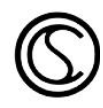




\section{Clima de opinión y proceso de paz en Colombia}

El conflicto armado, los procesos de paz con las Fuerzas Armadas Revolucionarias de Colombia-Ejército del Pueblo (FARC-EP) y el Ejército de Liberación Nacional (ELN), así como la implementación de los acuerdos de paz han estado en la agenda política y mediática nacional durante los últimos años (Charry, 2018; Gómez-Giraldo y Cárdenas-Ruíz, 2018; Sánchez, 2017; Sánchez, 2018). Por eso, fueron temas centrales en la campaña presidencial que se desarrolló durante el primer semestre de 2018, en la que finalmente triunfó el sector político opositor al proceso de paz y a los acuerdos firmados entre el entonces Gobierno del presidente Juan Manuel Santos y la guerrilla de las FARC. Dicho sector político, representando por el partido Centro Democrático y cuyo mayor referente es el ex presidente Álvaro Uribe Vélez, fue además el que impulsó la campaña por el "No" en el plebiscito por la paz de octubre de 2016 (Misión de Observación Electoral-MOE, 2016).

Durante la campaña presidencial, el Centro Democrático y su candidato, Iván Duque, abierta y continuamente manifestaron sus intenciones de modificar y ajustar los acuerdos de paz para impedir la impunidad; 8 por tanto, la campaña se dividió entre los simpatizantes y opositores de los acuerdos de paz.

8 Para conocer la posición del partido Centro Democrático e Iván Duque frente a los acuerdos de paz, véase: "Iván Duque: no queremos hacer trizas los acuerdos de paz", La FM, enlace:

https://www.lafm.com.co/politica/ivan-duque-no-queremos-hacertrizas-los-acuerdos-de-paz;
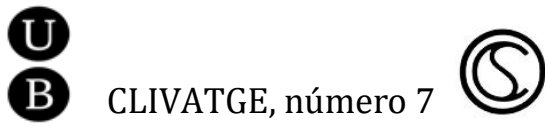
Por esta razón, se ha considerado pertinente contextualizar, a partir de encuestas, la opinión que se ha hecho pública acerca de la paz, los acuerdos de La Habana y su implementación durante el periodo electoral y en los primeros meses de Iván Duque como presidente de la República, esto con la intención de identificar el clima de opinión en torno a los temas que posteriormente se rastrearon en los medios de comunicación y que hicieron parte de la investigación. Esta exploración no se hizo con la intención de establecer correlaciones entre las opiniones manifiestas en las encuestas y lo publicado en los medios, sino para caracterizar la existencia de una tendencia pesimista alrededor de las posibilidades de paz, tanto en los medios de comunicación como en la ciudadanía.

\footnotetext{
"Nosotros no queremos hacer trizas los acuerdos: Iván Duque", La W, enlace: http://www.wradio.com.co/noticias/actualidad/nosotros-noqueremos-hacer-trizas-los-acuerdos-ivanduque/20180528/nota/3755084.aspx;

"El próximo Gobierno no podrá hacer trizas el acuerdo de paz con las Farc: Santos", El Espectador, enlace:

https://www.elespectador.com/noticias/politica/el-proximo-gobiernono-podra-hacer-trizas-el-acuerdo-de-paz-con-las-farc-santos-articulo791771;

"Es evidente que el uribismo quiere hacer trizas el acuerdo de paz: Roy Barreras", Semana, enlace:

https://www.semana.com/nacion/articulo/es-evidente-que-eluribismo-quiere-hacer-trizas-el-acuerdo-de-paz-roy-barreras/573406; "Hacer trizas' el acuerdo con las FARC: ¿es posible?", Semana, enlace:https://www.semana.com/nacion/articulo/uribismo-haratrizas-acuerdo-acuerdo-con-farc-esta-blindado/524529.
} 
No es nuestra intención discutir si las encuestas logran medir efectivamente la opinión pública, nos limitaremos a señalar que coincidimos con Pierre Bourdieu y otros autores, quienes afirman que la opinión que se recoge a través de encuestas presenta un alto grado de manipulación y que, más allá de problemas técnicos con el método y la muestra, la mayoría de la veces las encuestas realizan preguntas sobre temas acerca de los cuales los ciudadanos no necesariamente se cuestionan o tienen información suficiente para responder (Bourdieu, 2000). Por eso, es erróneo considerar que todas las personas tienen una opinión sobre los asuntos sobre los que se indaga. Igualmente, se sabe que este tipo de encuestas responden a coyunturas políticas particulares y no tanto a intereses de la ciudadanía, de ahí que: "las problemáticas que proponen las encuestas de opinión están subordinadas a intereses políticos, y esto pesa enormemente tanto sobre la significación de las respuestas como sobre la significación que se le confiere a la publicación de los resultados" (Bourdieu, 2000: 232).

En ese sentido, se comprende el alto número de encuestas que se realizaron en Colombia en 2018, pues además de las dos vueltas presidenciales, hubo elecciones parlamentarias y una consulta ciudadana sobre la corrupción.

En Colombia existen diversas firmas encuestadoras que se vinculan con medios de comunicación para realizar sondeos de opinión periódicamente, entre las más reconocidas y con mayor visibilidad se destacan: Polimétrica, encuesta periódica desarrollada por la empresa Cifras y Conceptos para Caracol Radio y Red + Noticias; 
Plataforma de Opinión Pública en Colombia, elaborada por Yanhaas para RCN Radio, Noticias RCN, La FM, El País, El Universal, El Colombiano, Vanguardia Liberal y La República; Pulso País, realizada por Datexco para La W Radio; además de Colombia Opina elaborada por Invamer para Noticias Caracol, Revista Semana y BLU Radio.

Para realizar esta contextualización se ha tomado información de las dos últimas encuestas señaladas, Pulso País, ${ }^{9}$ encomendada por La W Radio, y Colombia Opina, ${ }^{10}$ elaborada por encargo de Noticias Caracol, Revista Semana y BLU Radio. Existen tres razones por las cuales se eligieron estas encuestas: la principal está relacionada con que presentan preguntas concretas sobre temas de paz y la implementación de los acuerdos, tienen mayor cobertura geográfica; además de que comparan los resultados de la última medición con resultados de encuestas anteriores, lo que posibilita identificar tendencias en la opinión frente a los temas señalados.

${ }^{9}$ La encuesta Pulso País realizó cinco mediciones durante el 2018, en los meses de enero, abril, agosto, octubre y diciembre. Su universo poblacional fueron personas mayores de 18 años en zonas urbanas de seis regiones geográficas: Antioquia y eje cafetero, Llanos, Centro-Sur Amazonía, Caribe, Pacífico y Región Centro-Oriente. Para la medición de diciembre de 2018 se realizaron 900 encuestas telefónicas.

${ }^{10}$ Colombia Opina tuvo siete mediciones en el 2018: enero, marzo, abril, mayo, junio, septiembre y noviembre. Su universo fueron "hombres y mujeres mayores de 18 años, de todos los niveles socioeconómicos, residentes en Colombia, exceptuando los departamentos antiguamente llamados 'territorios nacionales' y las islas de San Andrés y Providencia". En la encuesta de noviembre de 2018 se cubrieron 46 municipios y se realizaron 1.080 encuestas. 
Por otra parte, conviene señalar que los asuntos que aluden a la paz, como la implementación de lo acordado con las FARC o los diálogos con el ELN, no se encuentran entre los principales problemas que los encuestados identifican como los más sensibles, pues, de acuerdo con datos de Colombia Opina, históricamente los ciudadanos han considerado el desempleo, la corrupción, la inseguridad, la salud, la educación, la pobreza y el narcotráfico como problemas prioritarios para el país, incluso por encima de la paz.

Acercándonos un poco a las preguntas sobre la paz, en la encuesta Colombia Opina se preguntó: "En su concepto, ¿la implementación del acuerdo entre el Gobierno y las FARC va por buen camino o mal camino?". El porcentaje de ciudadanos que señala que va por mal camino siempre ha sido superior a los que opinan lo contrario; es decir, que, entre mayo de 2017 y noviembre de 2018, la mayoría de los encuestados ha considerado que la implementación va por mal camino. Aquí cabe destacar que el pico más alto de este pesimismo se dio entre abril $(73,7 \%)$ y mayo $(72,1 \%)$ de 2018 , es decir, durante el periodo de mayor intensidad de la campaña presidencial.

Con relación a lo anterior, se debe señalar que el periodo de menor pesimismo se dio precisamente en septiembre de 2018 (55,6\%); es decir, un mes después a la toma de posesión de Iván Duque como presidente, quien representaba el sector opositor a los acuerdos con la guerrilla de las FARC y que llegó con la promesa de realizar ajustes a lo acordado con el grupo guerrillero, aunque el 
pesimismo frente a la implementación volvió a subir en noviembre de 2018 (67,1\%), la última medición del año.

El pesimismo evidenciado en estos datos se puede contrastar con la pregunta realizada por Pulso País en torno a la paz: “¿Se siente usted optimista o pesimista en que Colombia va a lograr construir la paz?". Aquí sucede algo similar a la pregunta sobre la implementación: el pesimismo siempre tiene un porcentaje mayor que el optimismo. Sin embargo, en agosto, durante el primer mes de Iván Duque, el porcentaje de personas optimistas frente a la paz llegó al 58,1\%, aunque en diciembre el pesimismo volvió a tener un porcentaje más elevado con un $51,4 \%$.

Con estas preguntas se puede constatar cómo las opiniones frente a la paz y la implementación de los acuerdos varía con las coyunturas políticas, pues durante la campaña presidencial se registró el mayor pesimismo, lo cual se relaciona con la centralidad que los temas de paz alcanzaron durante ese periodo y con la visibilidad lograda por el sector político que históricamente se había opuesto a los diálogos; de ahí que el nivel de pesimismo haya disminuido durante los primeros dos meses en los que Iván Duque, del Centro Democrático, se posesionó como presidente de la República, pues llegaba al poder el sector político que hizo campaña a partir de la modificación de los acuerdos. Sin embargo, después del mes de octubre, el escepticismo frente a la paz volvió a porcentajes elevados, aunque no tan altos como durante el periodo de campaña.

Esta tendencia hacia el pesimismo se complementa cuando en las encuestas se indaga por la confianza hacia la Jurisdicción Especial 
para la Paz (JEP), una de las instituciones garantes de la implementación de los acuerdos, ya que, según datos de Pulso País, el $56 \%$ de los encuestados manifestó desconfianza hacia esta institución, mientras que un 59\% consideró que las sanciones que impondrá la JEP no satisfarán a las víctimas. Por su parte, en Colombia Opina la imagen desfavorable de la JEP terminó el año con el 47\%, mientras que solo el $38 \%$ de los encuestados tenía una opinión favorable. Estos datos evidencian, no solo el pesimismo frente a la paz, sino la desconfianza con respecto a una de las instituciones bandera de la implementación de lo acordado.

Lo evidenciado en las opiniones sobre el acuerdo de paz con las FARC y su implementación, de alguna manera, condiciona los datos sobre los diálogos con la guerrilla del ELN; por eso, en las encuestas analizadas se puede observar un rechazo y una desaprobación frente a este proceso. En Colombia Opina se preguntó: “¿Está usted de acuerdo o en desacuerdo con que el Gobierno reanude las negociaciones con el ELN?"; el mayor porcentaje de la población encuestada manifestó estar en desacuerdo con dichas negociaciones; por eso, durante los primeros meses de la presidencia de Iván Duque la desaprobación de dichas negociaciones estuvo alrededor del $61,5 \%$.

En Pulso País se preguntó “¿Usted cree que el grupo del ELN tiene o no intenciones legítimas de llegar a un acuerdo de paz?". Entre agosto y diciembre de 2018; o sea, los primeros meses de Iván Duque como presidente, el escepticismo frente a las intenciones del ELN aumentaron, pues en la última medición cerca del $80 \%$ de la población 
encuestada no creía que el grupo guerrillero estuviera interesado en llegar a un acuerdo con el Gobierno.

De acuerdo con los datos presentados en las encuestas seleccionadas para esta contextualización, en el país existe un pesimismo y una desesperanza en torno a la paz. No obstante, esto no es un fenómeno aislado dentro de la opinión pública; por el contrario, se enmarca dentro de una negatividad frente a la realidad nacional, pues cuando en las encuestas se indaga por la opinión sobre el rumbo del país, el pesimismo vuelve a ser el protagonista. Por eso, cuando en Pulso País se pregunta “ ¿En general, Usted piensa que Colombia va por buen o mal camino?", el 71\% de los encuestados consideró que el país va por mal camino, aunque, como ocurrió con los asuntos de paz, durante los primeros dos meses de Duque como presidente el pesimismo disminuyó (58\%), aun cuando los porcentajes de ciudadanos que consideraban que iba por buen camino solo llegaron al 33\% en septiembre de 2018.

Estos resultados son similares a los arrojados por Colombia Opina, que formuló a sus encuestados la pregunta: "En general, ¿cree usted que las cosas en Colombia van por buen camino o por mal camino?", encontrando que para noviembre el porcentaje que consideraba que va por mal camino era del 73,8\%.

Y a pesar del amplio favoritismo con el cual llegó al poder, al ganar por un amplio margen en las dos vueltas electorales, cuando se interroga por la imagen del presidente de la República y por la aprobación de su gestión, los resultados siguen siendo negativos, pues de acuerdo a Pulso País, Iván Duque cerró el 2018 con una imagen 
desfavorable del 62\%; mientras que, según datos de Colombia Opina, en noviembre de 2018 el 64,8 \% de los encuestados desaprobaba la gestión del presidente.

De este modo, uno de los principales hallazgos que se pueden inferir de las encuestas de opinión seleccionadas para este análisis es que, si bien la paz ha sido uno de los temas centrales durante la última campaña presidencial, los datos de las mediciones muestran que no es un asunto prioritario para los ciudadanos encuestados, pues por encima de ella aparecen temas como el desempleo, la corrupción y la educación; por tanto, pareciera que la paz hace parte de las agendas política y mediática que se mueven de acuerdo con coyunturas e intereses partidistas y con fines electorales.

Otro hallazgo importante tiene que ver con el pesimismo y la desconfianza de la ciudadanía frente a las posibilidades de paz en el país, que, a pesar de no ser un tema prioritario, se enmarca dentro de la negatividad y la desesperanza frente a la realidad y el rumbo del país, pues, de acuerdo a los datos, los encuestados no creen que la implementación de los acuerdos con las FARC llegue a buen término, desconfían de las acciones y las labores de la JEP y desaprueban las negociaciones con el ELN; es decir, que la mayoría de las personas encuestadas tiene una opinión negativa frente al presente y futuro de lo que puede ocurrir con la paz en Colombia.

Así, convendría preguntarse qué relación tienen y cuáles son los posibles orígenes de estas tendencias que evidencian las encuestas de opinión, las cuales expresan un marcado pesimismo de los colombianos sobre la situación del país, así como de la posibilidad real 
de alcanzar la paz y la correcta implementación de los acuerdos. Desde nuestra perspectiva, tales tendencias tienen que ver con la manera como los medios de comunicación colombianos han abordado estos asuntos, cobertura que, como demostraremos a continuación, está fuertemente asociada a un modo de encuadre o marco de sentido primario (frame), tal y como los concibió en su momento el sociólogo norteamericano Erving Goffman, 11 noción que sería aplicada posteriormente, entre otros, en los trabajos de Snow y Benford (2000) y Snow (2007).

\section{El cubrimiento mediático de los acuerdos de paz durante los primeros meses del Gobierno de Iván Duque}

\subsection{Aspectos metodológicos}

Con el propósito de desarrollar el análisis sugerido, hemos seleccionado ocho medios de comunicación colombianos, tanto televisivos como escritos. El criterio de selección de tales medios tuvo como fin abarcar la mayor parte de la geografía nacional, por lo cual se tuvieron en cuenta medios tanto de cobertura nacional como de orden regional.

11 Para quien: "un marco de referencia primario es aquel que se considera que convierte en algo que tiene sentido lo que de otra manera sería un aspecto sin sentido en la escena [...] cualquiera que sea su grado de organización, todo marco de referencia primario permite a su usuario situar, percibir, identificar y etiquetar un número aparentemente infinito de sucesos concretos definidos en sus términos" (Goffman, 2006: 22).

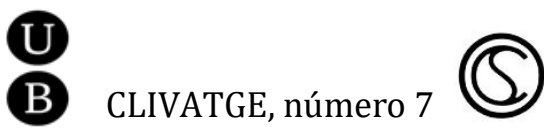


De este modo, fueron seleccionados los noticieros de los más grandes canales privados de televisión, Caracol y RCN, así como los periódicos que históricamente se han caracterizado por tener la mayor cobertura a nivel nacional, El Tiempo y El Espectador, ambos de la ciudad de Bogotá. Junto a estos medios fue incluida la influyente revista de opinión y análisis Semana y los más destacados periódicos regionales: El Colombiano de Medellín, El País de Cali y El Heraldo de Barranquilla.

Por su parte, como ha señalado Herminda (2010), existe una estrecha relación entre lo que los medios de comunicación emiten en sus canales tradicionales de información y lo que publican en Twitter, expresándose una relación de reflejo o duplicidad. A partir de dicho argumento, se ha optado por hacer un seguimiento pormenorizado de la producción informativa registrada en esa red social digital por los medios de comunicación escogidos para el análisis. Este ejercicio, además de permitir la contrastación de la información, también ha permitido su homologación, pues al estar en un mismo formato se pueden superar las particularidades técnicas propias de los canales tradicionales a través de los cuales estos medios mantienen informadas a sus audiencias, diferencias que impedirían un análisis riguroso, en particular, si se piensa en los profundos contrastes que existen entre medios audiovisuales y escritos.

Por su parte, la recolección de las noticias asociadas a los acuerdos de paz se obtuvo a partir de la aplicación de importación de datos de Twitter que tiene diseñada el software especializado en investigación mixta MAXQDA 2018, el cual permite hacer una captura 
de hasta diez mil tweets semanales. ${ }^{12}$ La recopilación de los eventos noticiosos partió de tomar las palabras "paz", "implementación", "acuerdos", "JEP" (que hace referencia a la Justicia Especial para la Paz) y "FARC" como motores de búsqueda y captura de datos. Esta información fue depurada y sistematizada en una base de datos en SPSS, a través de la cual se crearon diferentes tipos de variables, entre las que se cuentan el tipo y el sesgo noticioso, así como el actor principal de la noticia, siendo a su vez posible identificar el sesgo que el medio le atribuye a los principales actores de los eventos noticiosos.

Las noticias fueron clasificadas a partir de los puntos definidos para la implementación del acuerdo definitivo de paz firmado entre el Gobierno colombiano y la hoy extinta guerrilla de las FARC, entre los que se encuentran la restitución de tierras, la participación política, el enfoque de género, la lucha contra el narcotráfico, la participación y la reparación a las víctimas y la reinserción de los ex guerrilleros a la vida civil. A estas categorías se agregaron otras que consideramos igualmente importantes, tales como derechos humanos, medioambiente, disidencias, los diálogos de paz con el ELN, las reacciones que generan los acuerdos de paz de Colombia a nivel internacional, la puja y la controversia política a nivel interno, los procedimientos de la implementación, así como los temas de orden judicial.

Por su parte, el sesgo de la noticia fue categorizado entre "negativo", "neutral" y "positivo", a partir del proceso de adjetivación

12 Para mayor información, véase: www.maxqda.com. 
que existe en todo titular, el cual da cuenta del posicionamiento ideológico que tienen los editorialistas de cada medio, siendo el titular nuestra unidad de análisis primordial, dado que contiene el mayor peso cognitivo e informativo de la noticia, tal y como han señalado los estudios de Teun Van Dijk (1990, 1997 y 2000).

Entre tanto, los actores de la noticia considerados fueron el Gobierno, las FARC, los opositores y los simpatizantes de los acuerdos de paz, las disidencias de las FARC, las víctimas, la sociedad civil organizada, los militares (lo que hace referencia a todos los miembros o integrantes de las Fuerzas Armadas), los industriales, la Iglesia, las organizaciones no gubernamentales, los académicos, los miembros u organizaciones pertenecientes a la comunidad internacional, el ELN, los magistrados de la JEP, las altas cortes (Justicia, Constitucional y Consejo de Estado), los integrantes de grupos paramilitares que se hayan expresado en relación a los acuerdos de paz y su implementación, los partidos políticos $\mathrm{y}$, por último, los actores judiciales, categoría en la que se incluyeron actores noticiosos tales como la Fiscalía General de la Nación y jueces de la república.

Se creó una variable para sistematizar el sesgo atribuido por el medio a las acciones o declaraciones hechas por los diferentes actores noticiosos, la cual fue categorizada entre "en contra", "neutral" y "a favor" de la implementación de los acuerdos, incluyéndose también un "no aplica" (o N/A) en el caso de que la información emitida por el medio no permitiera dar cuenta de tal posicionamiento ideológico de los actores de la noticia. 
En total fueron registrados cerca de 2.900 hechos noticiosos, pero después de la depuración hecha quedaron 2.607 disponibles para el análisis que se propone. La captura de información se desarrolló entre el 1 de agosto y el 31 de octubre de 2018, durante un total de 13 semanas. En este proceso de indagación se tuvo en cuenta la frecuencia o número de veces que fue publicada ("twitteada") una noticia por el medio, pues ello evidencia que, para dicho medio, esa noticia fue más relevante que otras. Por último, se aclara que no se trata de una muestra con significación estadística, pues el software utilizado para esta indagación captura todos los tweets emitidos por el medio según los parámetros de búsqueda seleccionados.

Por otra parte, conviene señalar que, gracias a los estudios de Richard y Saffon (2016), sabemos que la televisión es el medio de comunicación con mayor cobertura a nivel nacional (cercana a un 95\% de los hogares) y que 9 de cada 10 colombianos accede a ella como medio de comunicación preferido para informarse y entretenerse, siendo seguida por la radio, internet y la prensa escrita, elementos que permiten hacerse una idea de la influencia que ejercen los medios de comunicación que hemos analizado, todo lo cual se ve reflejado en el número de seguidores que cada uno de ellos posee en Twitter, en donde Caracol Noticias contabiliza a la fecha más de 8 millones de seguidores, seguido por Noticias RCN con 7,4 millones; El Tiempo, con 6,5; El Espectador, con 4,6; la Revista Semana, con 4,1, y El Colombiano, con 1,8 millones; mientras que El Heraldo, de Barranquilla, cuenta con unos 996.000 seguidores y El País, de Cali, con cerca 630.000.

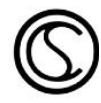




\subsection{La agenda de la paz en los medios de comunicación}

Lo primero que se puede apreciar en cuanto al cubrimiento dado por los medios de comunicación en relación con los acuerdos de paz durante los tres primeros meses del Gobierno de Iván Duque es que existen importantes diferencias en relación al volumen de información emitida, lo que da cuenta a su vez de cuáles fueron los medios para los cuales el tema de los acuerdos fue más transcendental o revistió mayor importancia, frente a otros medios cuya cobertura de este tema es significativamente menor.

Se identifica entonces una mayor atención de parte de los medios de comunicación cuya cobertura es de orden nacional frente a los de orden regional, cuyos porcentajes son mucho menores. El liderazgo de la cobertura informativa lo encabezó el periódico El Espectador, con un 24\%, seguido por Noticias RCN, con un 19,9\%, y El Tiempo, con un $15.6 \%$. Entre tanto, los medios con las más bajas tasas de cobertura informativa fueron El País de Cali con un 6,3\% y El Heraldo de Barranquilla, con un 6,2\% (véase el gráfico 1). 


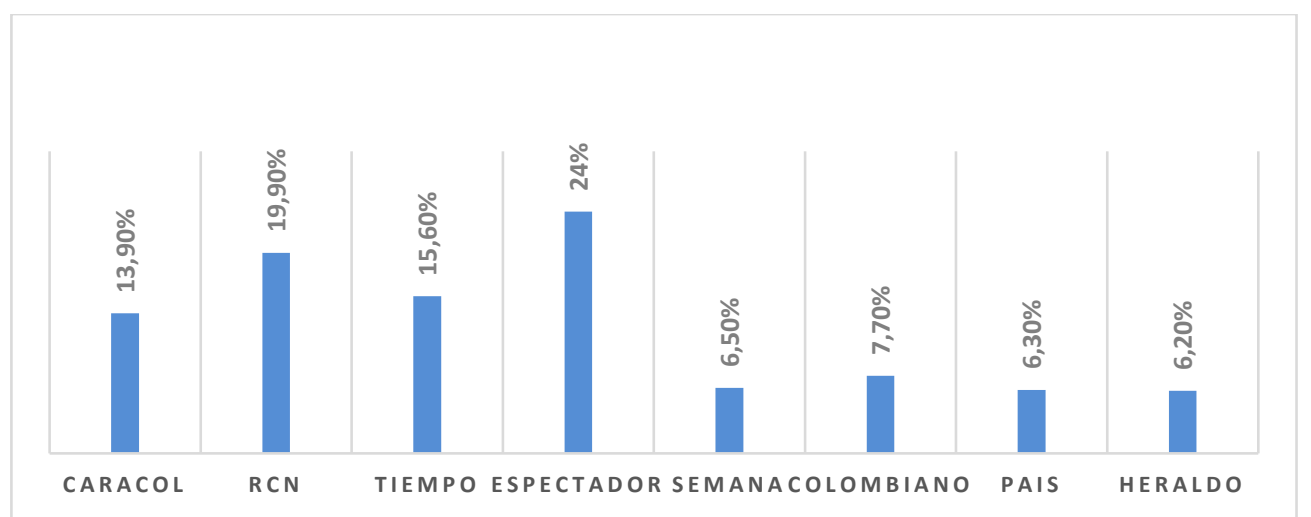

Gráfico 1. Distribución porcentual de cobertura informativa por medio

Del mismo modo, los medios de comunicación escogidos para el análisis mostraron una dinámica variable en el cubrimiento de los acuerdos de paz, expresándose una mayor cobertura entre las semanas 6,12 y 13 , con un 12\%, 12,4\% y 11,1\%, respectivamente (véase el gráfico 2).

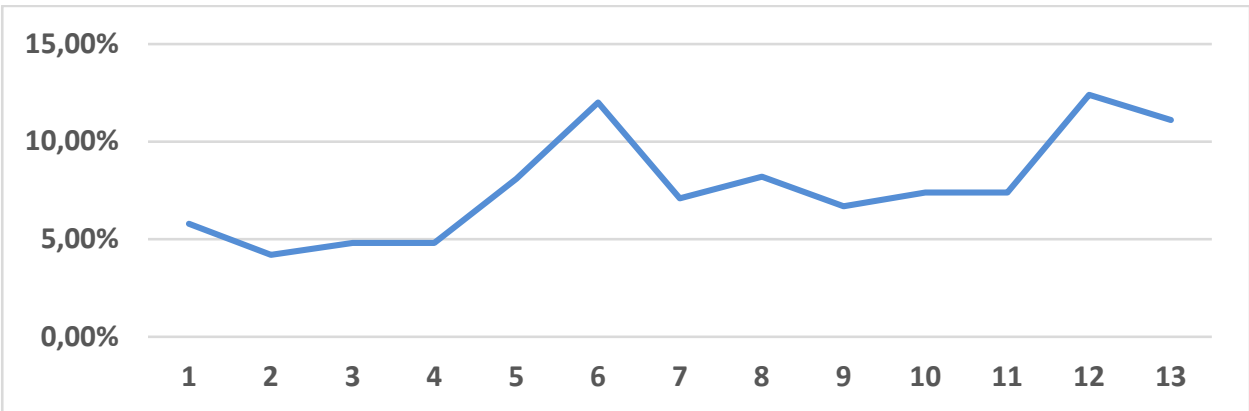

Gráfico 2. Distribución porcentual de cobertura informativa por semana

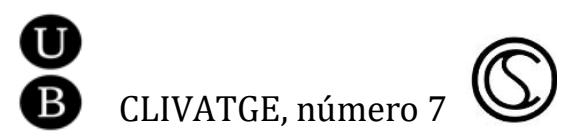


La semana 6 (del 6 al 13 de septiembre) estuvo asociada con dos coyunturas informativas. De una parte, se encuentran las tensiones y las discrepancias entre el Gobierno y el ELN en el proceso de acercamiento con miras a reanudar las conversaciones de paz, proceso que había emprendido hacia el final de su mandato el Gobierno anterior, pero que en este ha llegado a un estado de total estancamiento y casi ruptura. Por otra parte, el otro tema que logró impactar informativamente durante esa semana fue la confirmación por parte de una comisión de las Naciones Unidas de la salida de los espacios territoriales de paz de seis miembros de alta jerarquía de las FARC; entre ellos, el líder de la comisión negociadora de los acuerdos, alias “Iván Márquez", y de las personas de alias "Romaña” y de alias "el Paisa". Estos hechos habrían ocurrido la semana anterior, pero solo habrían podido ser constatados días después. Estos sucesos daban a entender a la opinión pública colombiana la existencia de una crisis en el proceso de implementación de los acuerdos, a raíz de las diferencias que expresaban las FARC con el Gobierno entrante.

Por su parte, la semana 12 (del 18 al 24 de octubre) estuvo marcada por la comparecencia de las víctimas de las FARC para rendir su testimonio libre ante la JEP, escenario en donde se dieron crudas narraciones de la experiencia vivida por personas que fueron secuestradas por esa guerrilla, así como de los familiares de las personas que fallecieron a manos del entonces grupo armado ilegal.

Finalmente, la semana 13 (del 25 al 31 de octubre), la atención de los medios se concentró en los testimonios de las víctimas de las FARC ante la JEP que habían empezado la semana anterior, así como 
en la polémica que se desató tras la no aprobación de las curules para la paz, medida que forma parte de la participación política de las víctimas del conflicto armado, iniciativa que fue denegada por tercera vez en el Congreso a pesar de que las diferentes bancadas políticas se habían puesto de acuerdo en aprobarlas en una reunión que contó con el encuentro - por primera vez- de los congresistas del partido político de las FARC y de la bancada del partido Centro Democrático, liderada por el ex presidente y senador Álvaro Uribe Vélez, quien luego de una serie de conversaciones accedió a su aprobación, en una decisión que, por lo demás, no se vio reflejada en la votación parlamentaria que debió haberlas aprobado.

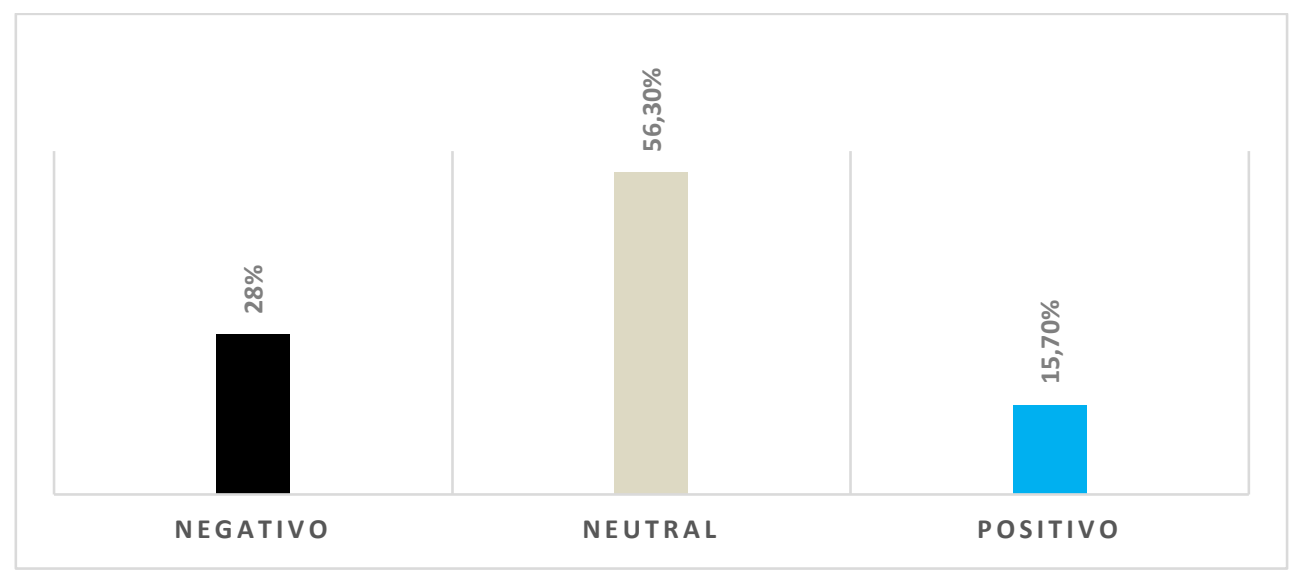

Gráfico 3.1. Distribución porcentual de cobertura informativa por sesgo

Por otra parte, al observar el comportamiento de una variable que resulta central para el análisis como es el sesgo o el encuadre construido por los productores mediáticos de la noticia desde el 
titular, tenemos que la tendencia general fue una en la que impera el enmarcamiento "neutral", con un 56,3\%, seguido por el encuadre "negativo", con un 28\%, siendo apenas el 15,7\% el encuadre positivo (véase el gráfico 3.1). Estos datos nos permiten afirmar preliminarmente- que los medios de comunicación expresaron una tendencia neutral/negativa a la hora de informar a sus audiencias sobre el desarrollo que han tenido los acuerdos de paz durante el inicio del Gobierno de Iván Duque, una situación que se complejiza aún más al analizar la variación que tuvo el sesgo informativo semana a semana, en donde encontramos que el porcentaje más alto de encuadre negativo estuvo asociado con la semana 5 (30 de agosto al 7 de septiembre) con un $42,5 \%$, mientras que el sesgo positivo más alto estuvo presente en la semana 1 (del 1 al 7 de agosto), con un 36.7\%, semana que junto con las número 2 y la 3 fueron las únicas en la que el sesgo positivo se impuso sobre el sesgo negativo (véase el gráfico 3.2).

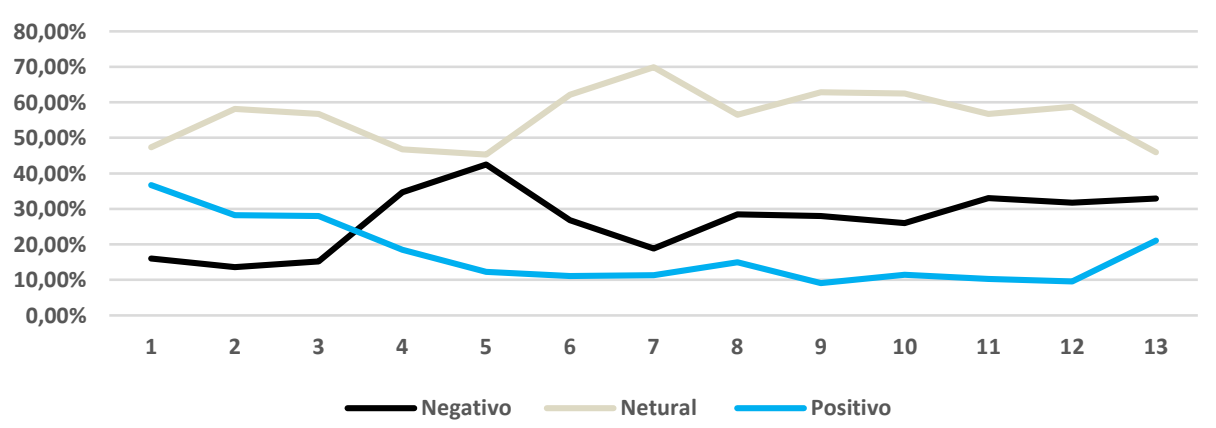


Gráfico 3.2. Distribución porcentual de cobertura informativa por sesgo y semana

Estas tendencias están asociadas con las declaraciones que hiciera el presidente Duque en su toma de posesión como mandatario de los colombianos, en donde afirmó que no haría "trizas los acuerdos" con las FARC, tal y como algunos líderes de su partido político, el Centro Democrático, habían afirmado con vehemencia durante la campaña. Todo ello enviaba un mensaje positivo frente a la continuidad de los acuerdos. Entre tanto, el abultado sesgo negativo asociado a la semana 5 está relacionado con la salida de "Iván Márquez", de "Romaña" y de "el Paisa" de los espacios territoriales de paz que fueron dispuestos para la concentración y reincorporación a la vida civil de los ex combatientes de la FARC, tal y como lo habíamos señalado anteriormente.

En cuanto al tipo noticioso (véase el gráfico 4.1), vemos que la mayor parte de la cobertura mediática estuvo asociada con la JEP $(27,5 \%)$, seguido por el tema de los procedimientos de implementación de los acuerdos (16,8\%), mientras que en tercer lugar se encuentran las noticias asociadas con el tema de las víctimas (9,9\%), lo cual representa un avance si se compara con la poca visibilidad dada por los medios de comunicación colombianos a las víctimas durante la fase de negociación de los acuerdos, entre 2012 y 2016, tal y como han señalado algunos estudios (Charry, 2018).

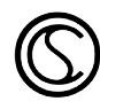




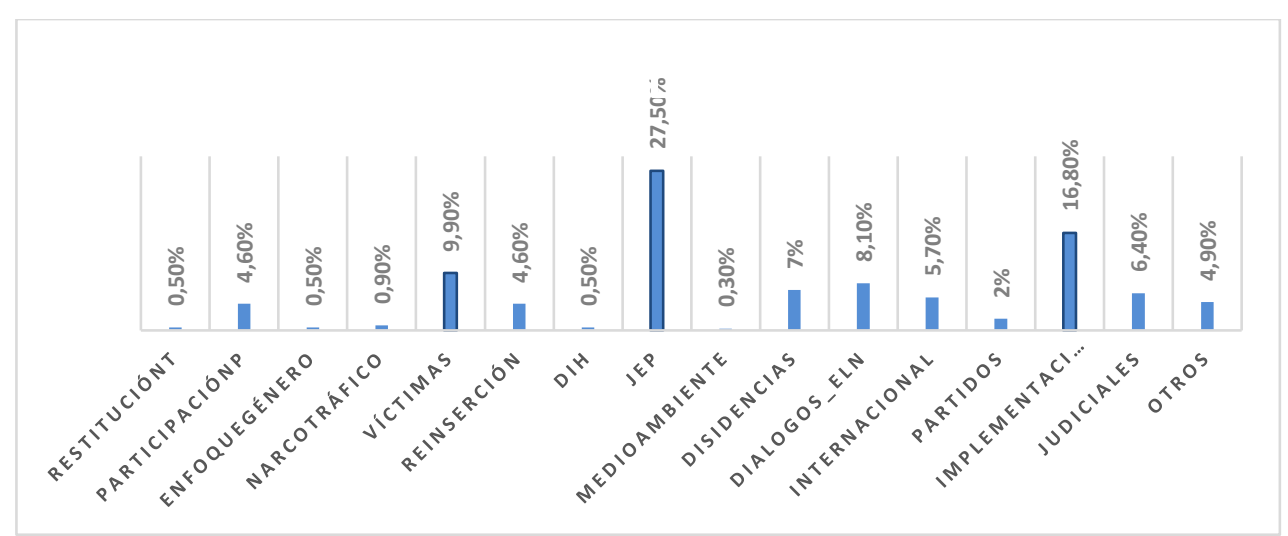

Gráfico 4.1. Distribución porcentual de cobertura informativa por tipo

Entretanto, al analizar la distribución del tipo noticioso respecto del medio, medida en número de casos (véase el gráfico 4.2), encontramos que en todos los medios dominó el tema de la JEP, con excepción de El Espectador, donde dominó el tema de la implementación. Igualmente, resulta interesante observar que este medio fue el que más información publicó sobre el tema de las víctimas, la reinserción y los derechos humanos; mientras que Noticias Caracol y RCN Noticias fueron los que más cobertura desplegaron en relación con el tema de las disidencias de las FARC. Por su parte, El Heraldo fue el medio de comunicación que más informó sobre el tema de la participación política de las FARC. 


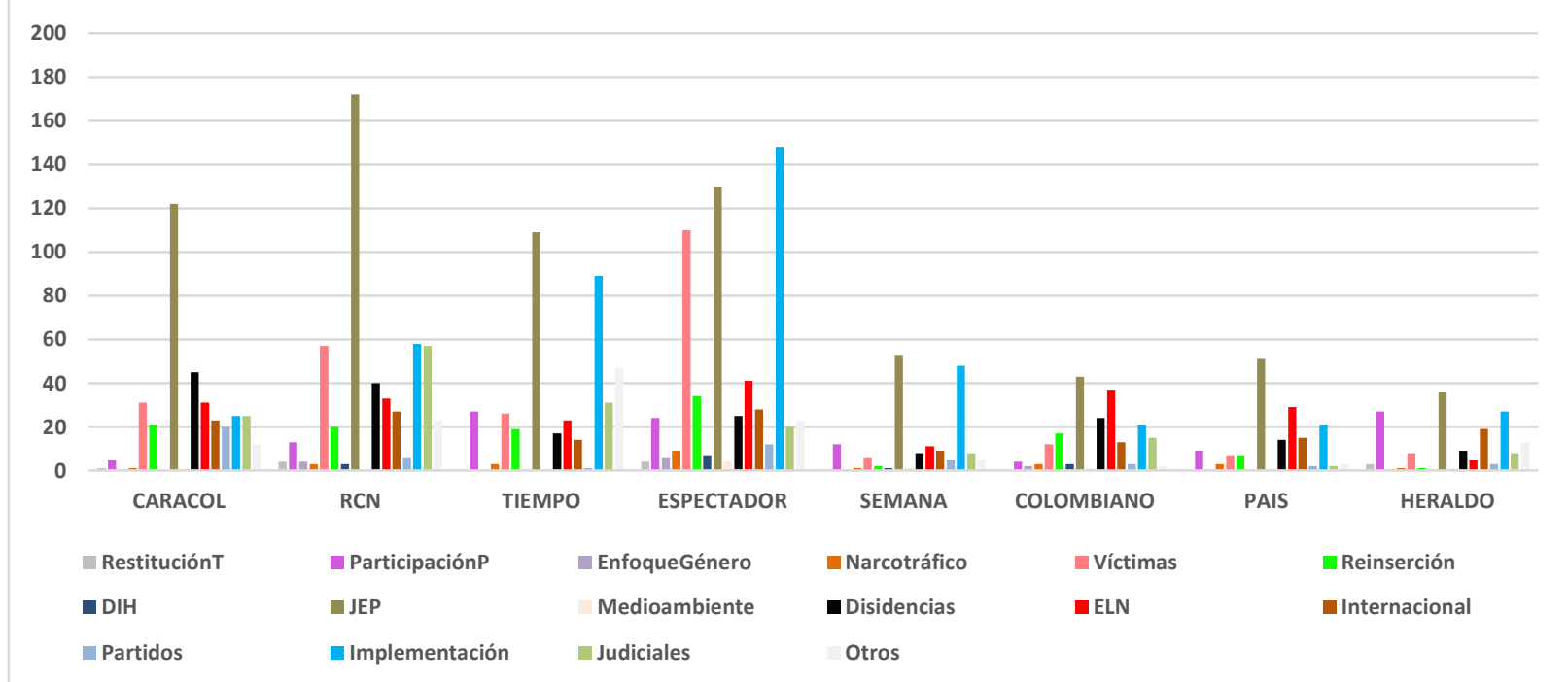

Gráfico 4.2. Distribución en número de casos de cobertura informativa por tipo y medio

Por su parte, al analizar el tipo noticioso respecto del sesgo general atribuido por el medio a la noticia (véase la gráfica 4,3), podemos apreciar que tanto el sesgo "neutral" (32,6\%), como el "negativo" (22,7\%) están dominados por las noticias asociadas con la JEP, mientras que el sesgo positivo, a pesar de que es minoritario, es dominado por el proceso de implementación (23,8\%). Esta situación está estrechamente asociada con los escándalos que rodearon la puesta en marcha de la JEP, en la que los medios informaron de una posible malversación de fondos por parte del primer presidente de esta jurisdicción especial, así como de las discrepancias dadas entre esta y la Fiscalía General de la Nación a raíz del sonado caso del alias 
"Jesús Santrich", miembro del antiguo "secretariado" de las FARC, quien fue involucrado por el ente acusador en un proceso por presunto delito de narcotráfico que habría ocurrido después de la firma de los acuerdos. Esta situación no sólo le daría la pérdida de los beneficios que adquirió al momento de la firma de los acuerdos, sino que además implicaría su inminente extradición a los Estados Unidos. El choque de trenes entre la JEP y la Fiscalía llegó hasta el punto de que la Fiscalía acusó a algunos magistrados de la JEP de filtrar información sensible de procesos a ex miembros de las FARC, e incluso del allanamiento de las instalaciones de la JEP por parte del ente acusador. 


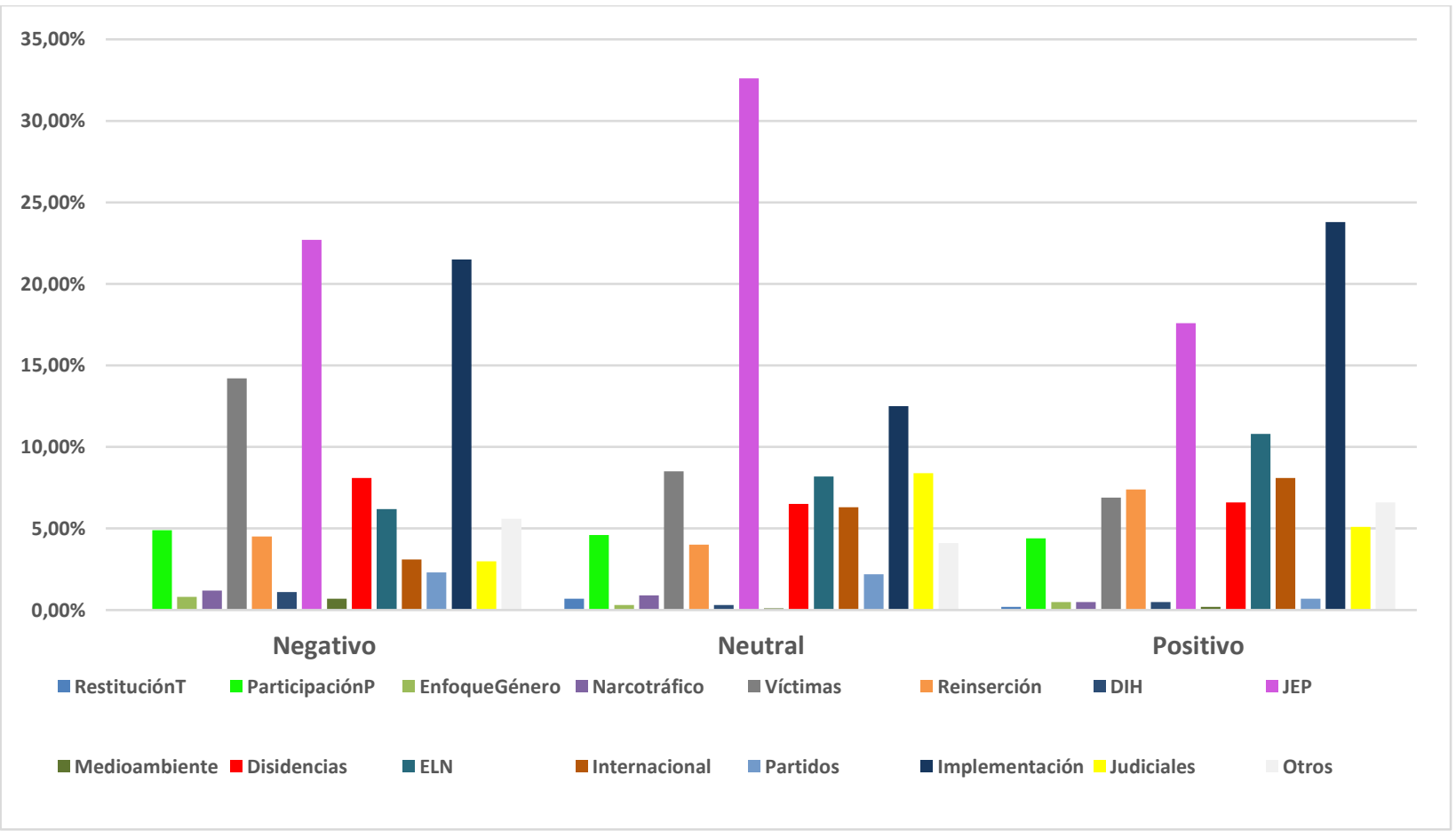

Gráfico 4.3. Distribución porcentual de cobertura informativa por tipo y sesgo

Por último, en relación con los actores mediáticos más relevantes (véase el gráfico 5.1), tenemos que los más visibles durante los tres meses de análisis fueron el "Gobierno" (19,9\%) y las "FARC" $(17,5 \%)$, seguidos - por menos de la mitad- por las "victimas" (8,9\%) y los "magistrados de la JEP" (8,9\%). Entretanto, al analizar la distribución por actores respecto del sesgo que el medio les atribuye en relación con la implementación de los acuerdos (véase el gráfico 5.2), encontramos a su vez que el actor de la noticia con mayor encuadre "a favor" de la implementación de los acuerdos es el
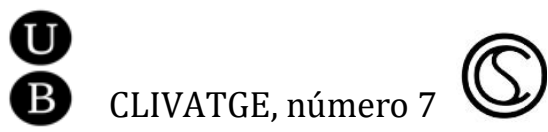
Gobierno, con un 26,6\%, seguido por las FARC, con un 15,8\% y las víctimas; mientras que el actor con el mayor encuadre "en contra" es las FARC, con un 24,2\%, seguido del Gobierno con un $13,2 \%$ y las disidencias de las FARC, con un 9,7\%.

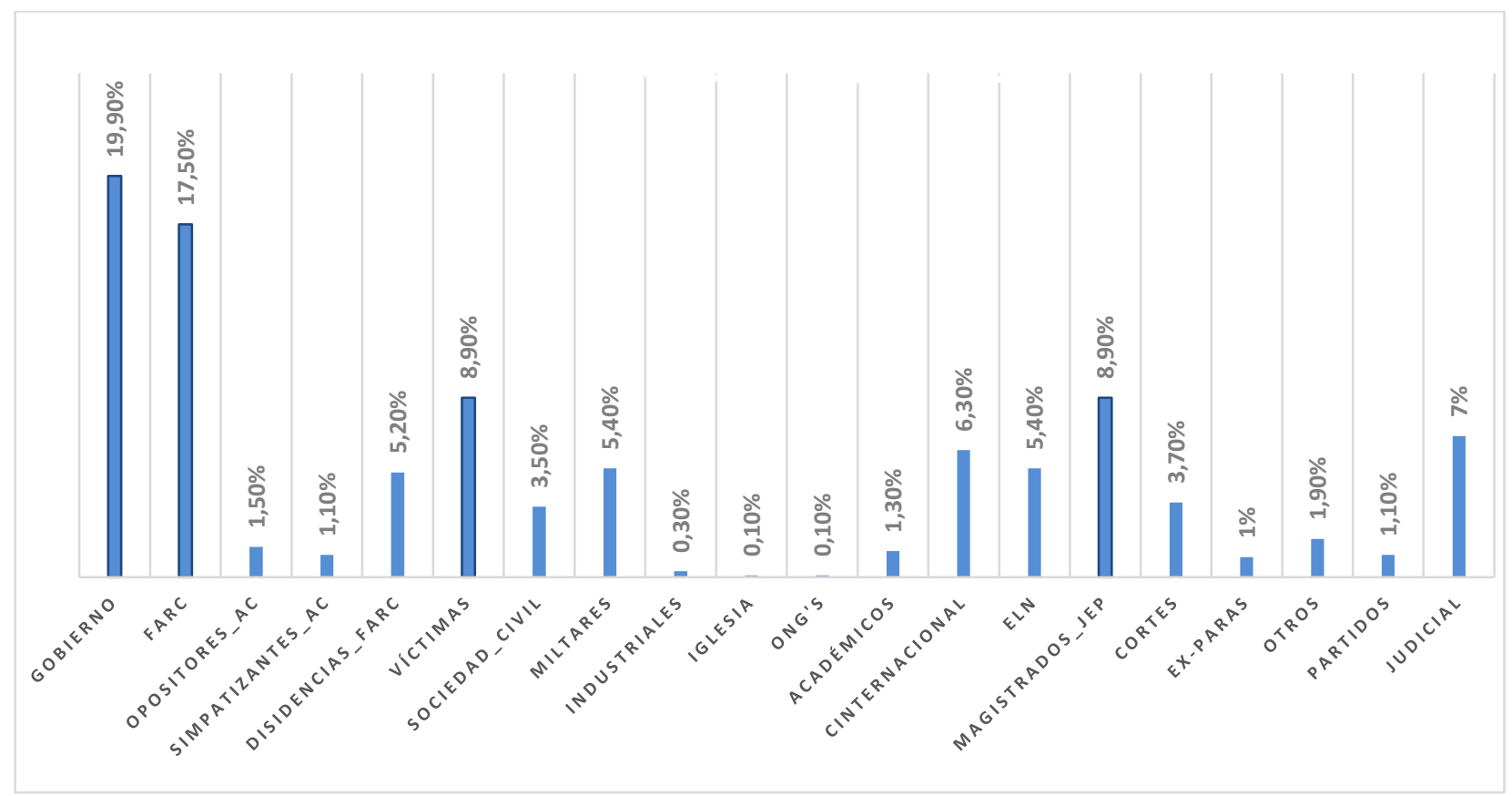

Gráfico 5.1. Distribución porcentual de cobertura informativa por actor

B Clivatge, número 7 ( 


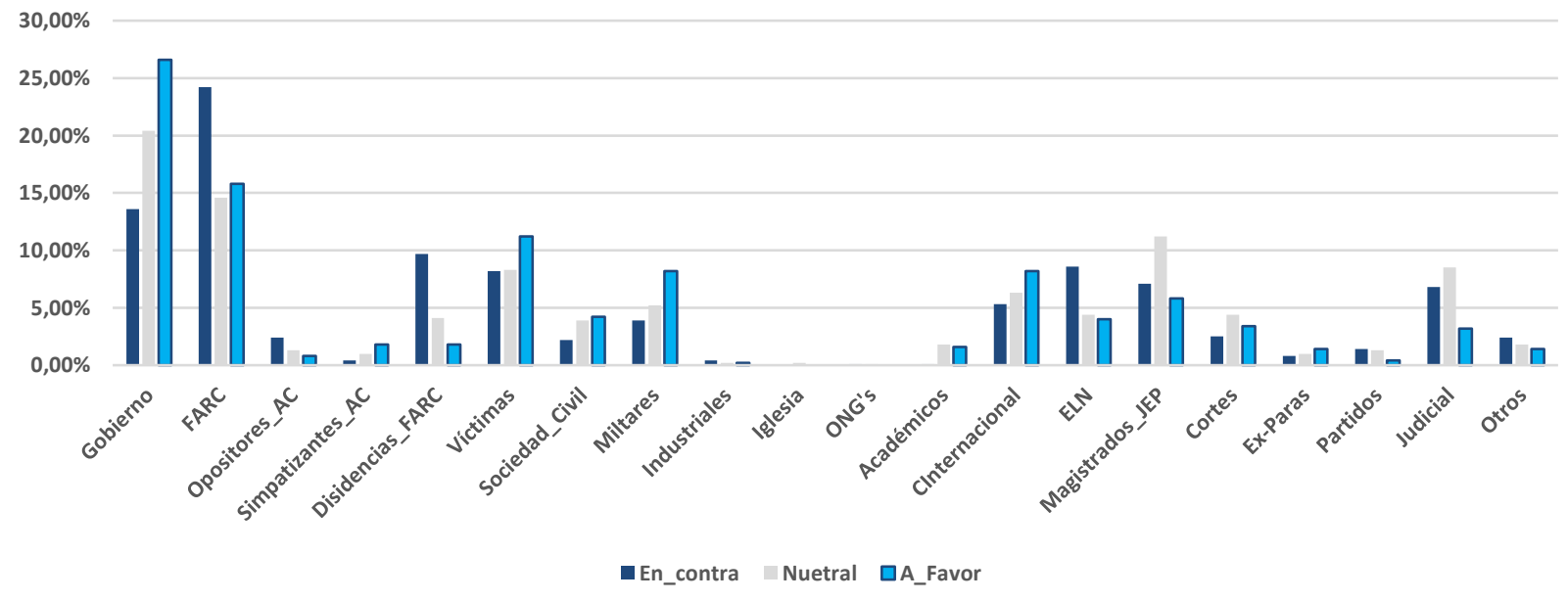

Gráfico 5.2. Distribución porcentual de cobertura informativa por actor y sesgo del actor

Esta información revela que, para los medios, los actores sobre los cuales recae la implementación de los acuerdos son el Gobierno y las FARC, cada uno de los cuales cumple una función diferente, a favor y en contra, siendo las víctimas un actor importante a la hora de hablar a favor de la implementación de los acuerdos, mientras que las disidencias de las FARC juegan un papel contrario, es decir, suelen ser un actor importante a la hora de hablarse en contra.

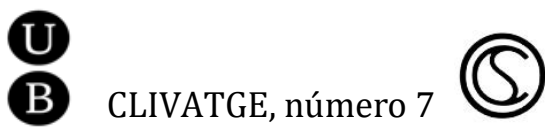




\subsection{A propósito de redes de asociación semántica y procesos de formación de opinión pública en torno a los acuerdos de paz}

A pesar de las importantes relaciones que hemos podido establecer hasta el momento, que dan cuenta de la manera como los medios de comunicación establecieron una agenda informativa respecto de los acuerdos de paz durante los tres primeros meses del nuevo Gobierno, el análisis propuesto quedaría incompleto si no atendemos a otras dimensiones analíticas. Hacemos referencia a las redes de asociación semántica desplegadas por los medios de comunicación en relación con el sesgo informativo, las cuales pueden ser consideradas como el cúmulo cognitivo que le queda a un consumidor mediático a la hora consultar las noticias que los medios emiten.

Al acercarnos a esta dimensión analítica podremos tener una idea aproximada, de carácter cualitativo, sobre la manera como los medios trataron de proyectar una imagen o representación de los acuerdos. Para ello, se requiere identificar las palabras más frecuentes expuestas en los titulares, asumiendo cada una de ellas como una unidad portadora de sentido, y, del otro lado, prestar atención a las asociaciones semánticas que se despliegan de tales palabras respecto del universo significativo compuesto por todos los titulares asociados a un tipo de sesgo.

Para tales fines, hemos dividido los titulares de las noticias según el sesgo, entre negativo y positivo, dado que los titulares clasificados como neutrales no permiten ver el posicionamiento ideológico de los medios, ejerciendo además un efecto normalizador

B CLIVATGE, número 7

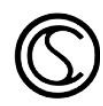


que imposibilitaría apreciar las diferencias y encontrar los puntos de contraste.

Así, encontramos que las palabras más frecuentes dentro los titulares clasificados por su sesgo como "positivos" fueron, en su respectivo orden: "paz", "JEP”, "FARC”, “Colombia” y “Gobierno"; mientras que las palabras más frecuentes en los titulares clasificados como "negativos" fueron en su orden: "FARC", "JEP", "paz", "no" y "Colombia"; lo cual es un hallazgo revelador al tratarse de una lista de palabras organizadas jerárquicamente, siendo claro que en los titulares clasificados como "negativos" la palabra que aparece en el primer puesto es "FARC" y cuenta en su lista con la palabra "no" como una de las más frecuentes.

Esto se ve reflejado en las redes de asociación semántica que tales conjuntos de palabras constituyen, las cuales se configuran a partir del cruce entre las palabras más frecuentes con el universo textual al que pertenecen, que en este caso son todos los titulares asociados a uno de los sesgos (positivo/negativo), del cual emerge un coeficiente de coaparición de palabras 13 que puede ser posteriormente graficado, ${ }^{14}$ evidenciando con ello las asociaciones semánticas más fuertes.

13 Para la realización del coeficiente de coaparición de palabras se usó el programa Fulltex desarrollado por el sociólogo holandés Loet Leydesdorff. Para mayor información al respecto véase: https://www.leydesdorff.net/.

14 Para la graficación de las redes de asociación semántica se utilizó el software PAJEK, el cual muestra las relaciones de asociatividad más 


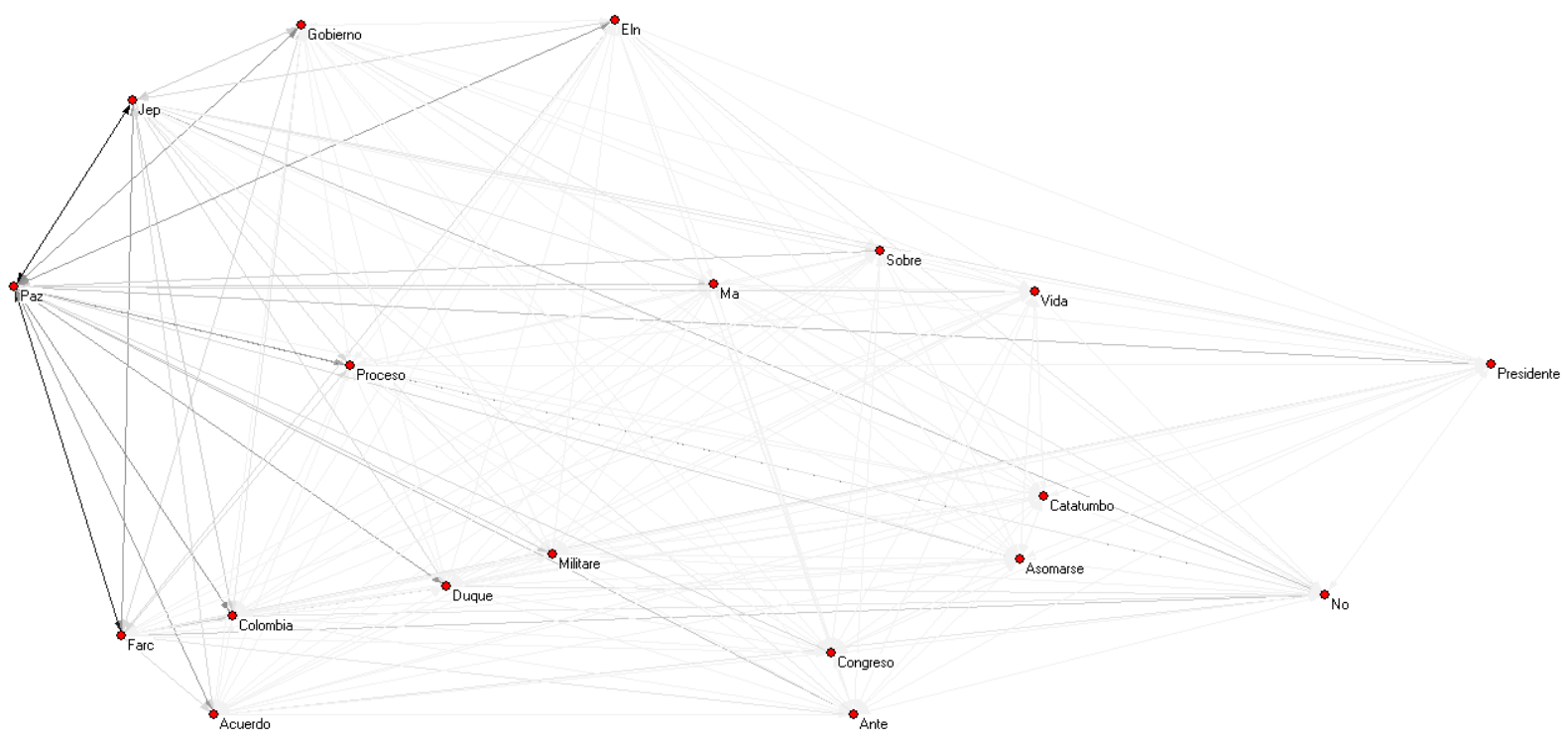

Gráfico 6.1. Redes de asociación semántica. Titulares con sesgo positivo

Es así como en las redes de asociación semántica más fuertes en relación a los titulares clasificados por el sesgo como "positivos" encontramos que existe una fuerte asociación entre las palabras "Paz", "Jep" y "Farc"; y de estas a su vez con "Gobierno", "proceso", acuerdos y "Colombia", como se ejemplifica en la gráfica 6.1.

Entretanto, en los titulares que por el sesgo fueron clasificados como "negativos", vemos que existe una sólida red de asociación semántica entre las palabras "FARC", "paz" y “JEP”, pero contrario a la

fuertes a partir de una escala de colores grises, siendo las más oscuras las más fuertes y las más claras las más débiles.
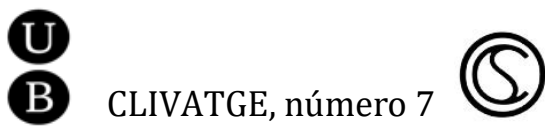
red de asociación semántica positiva, en este caso este conjunto de palabras o unidades significativas, se asocia con la palabra "no", "Fiscalía" y "ELN", entre otras, tal y como puede apreciarse en el gráfico 6.2; todo lo cual da cuenta de qué tipo de representaciones construyeron los medios de comunicación escogidos para el análisis en relación con los acuerdos de paz durante los tres primeros meses del actual Gobierno.

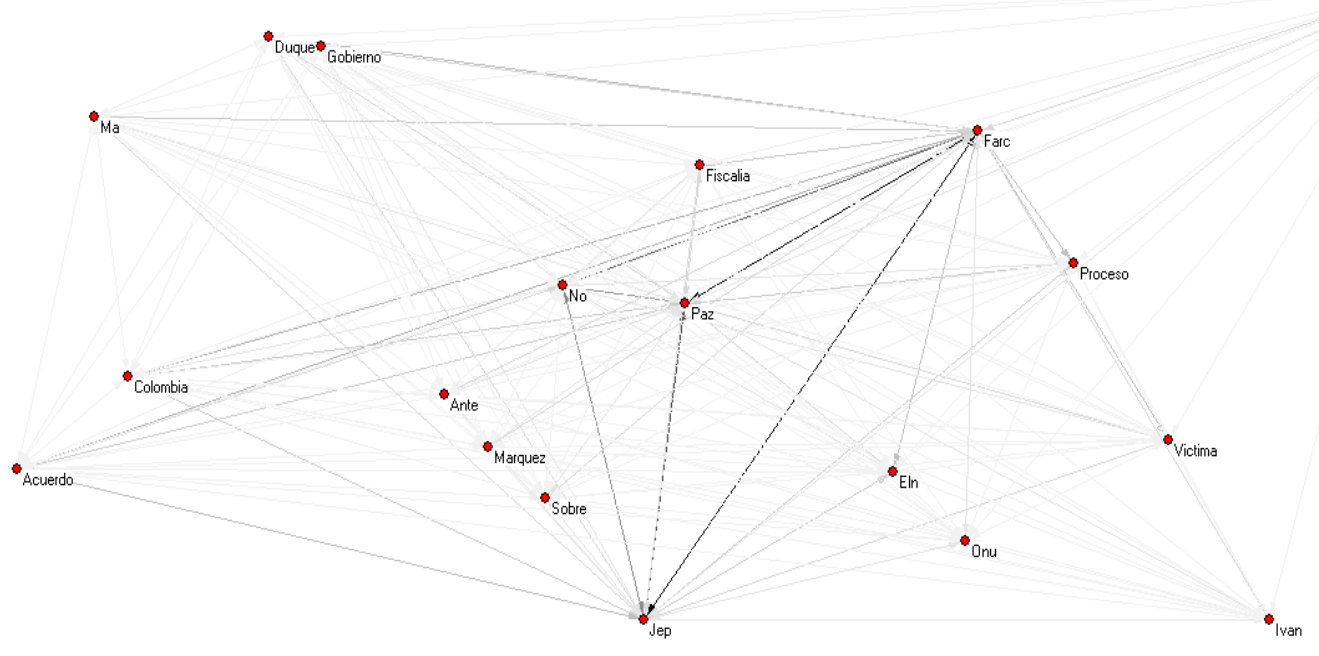

Gráfico 6.2. Redes de asociación semántica. Titulares con sesgo negativo

Esta información resulta trascendental si se considera que existieron medios en los cuales la diferencia entre sesgos fue mucho

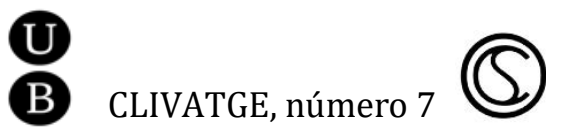


más abultada que en otros, tal y como se muestra en el gráfico 7 y su tabla adjunta, en donde no sólo se identifica que la mayoría de los medios de comunicación más influyentes o con mayor cobertura (El Tiempo, El Espectador y Caracol Noticias), tuvieron una tendencia más negativa, sino que, en general, al analizar esta dimensión se encuentra que en todos los medios escogidos para el análisis la favorabilidad de los acuerdos de paz tiende a ser negativa.

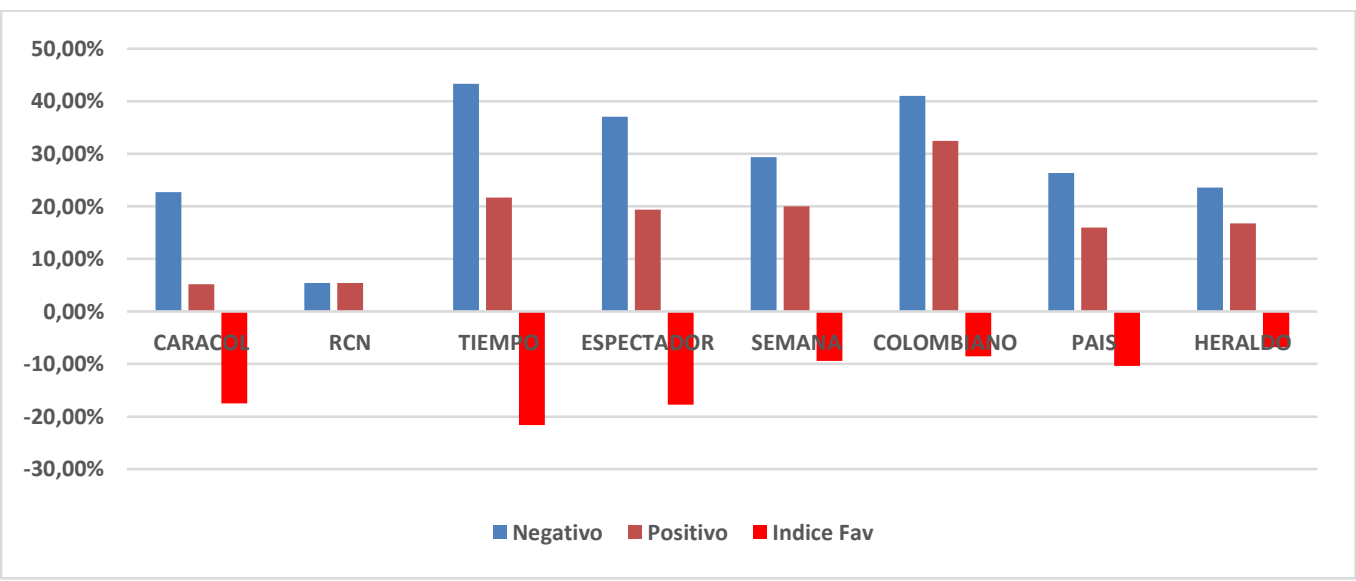

Gráfico 7. Índice de favorabilidad por medio

\begin{tabular}{|c|c|c|c|}
\hline & SESGO NEGATIVO & $\begin{array}{c}\text { SESGO } \\
\text { POSITIVO }\end{array}$ & $\begin{array}{c}\text { INDICE } \\
\text { FAV. }\end{array}$ \\
\hline TIEMPO & $43,30 \%$ & $21,70 \%$ & $-21,60 \%$ \\
\hline ESPECTADOR & $37,10 \%$ & $19,40 \%$ & $-17,70 \%$ \\
\hline CARACOL & $22,70 \%$ & $5,20 \%$ & $-17,50 \%$ \\
\hline PAIS & $26,40 \%$ & $16,00 \%$ & $-10,40 \%$ \\
\hline SEMANA & $29,40 \%$ & $20,00 \%$ & $-9,40 \%$ \\
\hline COLOMBIANO & $41,00 \%$ & $32,50 \%$ & $-8,50 \%$ \\
\hline
\end{tabular}

B CLIVATGE, número 7 


\begin{tabular}{|c|c|c|c|} 
HERALDO & $23,60 \%$ & $16,80 \%$ & $-6,80 \%$ \\
\hline RCN & $5,40 \%$ & $5,40 \%$ & $0,00 \%$ \\
\hline
\end{tabular}

Tabla 7. Índice de favorabilidad por medio

\section{Conclusiones}

La información suministrada por esta investigación nos ha permitido identificar que los factores de ambivalencia y negatividad —así como el denominado sesgo de negatividad-, que suelen configurar y determinar lo que es noticiable, han sido factores cruciales en el cubrimiento mediático de los acuerdos de paz y, en general, del tema de la paz en Colombia durante los primeros meses del nuevo Gobierno, temática que suele ser presentada más como un problema más que como una solución.

Tal afirmación la hacemos a partir del contraste de la información que emiten las encuestas de opinión con los datos que fueron recabados y analizados a partir de la base de datos que fue construida. Los procedimientos y análisis que fueron desarrollados nos permiten hacer visible un preocupante y bajísimo índice de favorabilidad por parte de los medios de comunicación colombianos respecto de los acuerdos de paz y su implementación.

Tal tendencia no solo se ve reflejada en que el sesgo negativo fue mayor que el sesgo positivo, sino en el hecho de que las coyunturas con mayor cobertura mediática que pudieron ser identificadas estuvieron asociadas con temáticas negativas (o "malas noticias"), como fueron las controversias del Gobierno o de la Fiscalía con la JEP, así como la salida de los espacios territoriales de paz de influyentes 
líderes de las FARC, o bien, con la imposibilidad de concretar la reactivación de las conversaciones de paz con el ELN. De hecho, los análisis elaborados nos han permitido saber que el sesgo positivo estuvo por encima del negativo durante las tres primeras semanas de agosto, es decir, solo cubrió las dos primeras semanas del Gobierno entrante. Desde allí se evidencia una tendencia negativa, que se ve reflejada y coincide con la tendencia pesimista que informan las encuestas de opinión sobre la situación del país.

A su vez, pudimos identificar que, si bien el Gobierno y las FARC son los principales actores de las noticias, el primero es más frecuentemente asociado con el sesgo positivo, mientras que el segundo se relaciona con el sesgo negativo, siendo las víctimas y las disidencias de las FARC actores mediáticos que contribuyen a reforzar dicha dicotomización, al relacionarse las victimas con el sesgo positivo, mientras que las disidencias de las FARC se identifican con el sesgo negativo.

Simultáneamente, hemos podido establecer que la Jurisdicción Especial para la Paz (JEP) ha sido la temática con el mayor encuadre negativo, mientras que el tema de la implementación de los acuerdos fue usualmente referenciado con el encuadre positivo, lo cual, en términos generales, configura una inmensa paradoja o ambivalencia, que sucumbe ante la cotidianidad de la puja político-partidista que generan estos temas, terminando por transformarse en pesimismo y negatividad. Una "ambitendencia" que se desprende del enfoque noticioso prevaleciente al centrarse casi siempre en aquellos hechos socialmente controvertibles. 
Tal disyuntiva se convierte en un reto ético y profesional para los editores mediáticos y para los reporteros que cubren el proceso de paz en Colombia, dado que existen elementos que evidencian un avance significativo en la sociedad colombiana, tal y como lo son las reducciones de muertes violentas (las más bajas en los últimos 40 años), así como la disminución de hostigamientos y enfrentamientos entre grupos armados ilegales y miembros de las Fuerzas Armadas, hechos que hace solo algunos años colmaban los titulares de los diferentes medios de comunicación. Igualmente, esta dinámica ha permitido que los procesos de formación de la opinión pública se descentren de la preponderancia de una agenda informativa arraigada en el conflicto armado interno y comiencen a visibilizar otras problemáticas, como la corrupción que carcome las instituciones, la pésima cobertura estatal en la prestación de servicios esenciales como la salud y la educación, así como la visibilización de los hechos de violencia de género o la reciente crisis migratoria venezolana.

A pesar de ello, todo indica que las exiguas intenciones de paz expresadas por el ELN han terminado de manera abrupta con las esperanzas de reanudar los diálogos con el Gobierno, tras el ataque terrorista con carro bomba efectuado hacia mediados de enero de 2019 en una escuela de formación de cadetes de la Policía apostada en Bogotá, hecho que dejó más de una veintena de muertos. Todo ello presupone que ha llegado el momento de poner a prueba los avances obtenidos en los acuerdos de paz y su implementación para que sirvan de contención a acciones irracionales que pueden motivar escenarios 
guerreristas y espirales de violencia en las que los medios de información jugarán un rol predominante para superar la agenda de la guerra, tradicionalmente ambivalente, tensionante y negativa, por una más propositiva que matice las noticias en torno a la paz como un hecho alcanzable Colombia.

\section{Referencias bibliográficas}

Aguiar, L. (2014). "O jornalismo em múltipla e paradoxal (trans) mutação". Jornalista em mutação. Do cão de guarda ao mobilizador de audiência. Florianopolis: Editora Insular: 11-17.

Capella, J. N. y Jamieson, K. H. (1997). Spiral of Cynicism: The Press and the Public Good. Nueva York: Oxford University Press.

Charry, C. (2018). "Rastreando la paz. Medios de comunicación y formación de opinión pública en torno al proceso de paz en Colombia". En Carlos Charry (ed.), Ciudadanías conectadas, sociedades en conflicto. Investigaciones sobre medios de comunicación, redes sociales y opinión pública. Bogotá: Universidad del Rosario.

Datexco. (2018, diciembre). Pulso País Colombia. Bogotá: Datexco Company S. A. - Opinómetro.

Galimberti, U. (2002). Diccionario de Psicología. Madrid: Siglo XXI Editores: 58-59.

Galtung, J. y Ruge, M. (1994). “A estrutura do noticiário estrangeiro: a apresentação das crises do Congo, Cuba e Chipre em quatro jornais estrangeiros". En Nelson y Traquina (eds.). Jornalismo: questões, teorias e estórias. Lisboa: Veja: 61-73. 
Goffman, E. (2006). Frame análisis. Madrid: Centro de Investigaciones Sociológicas.

Gómez-Giraldo, J. y Cárdenas-Ruíz, J. (2018). "El papel de la opinión publicada en la prensa escrita colombiana antes del plebiscito del 2 de octubre de 2016". Palabra Clave 22(1): 204-253. DOI: 10.5294/pacla.2019.22.1.9.

Hermida, A. (2010). "Twittering the news". Journalism Practice 4 (3): 297-308.

Invamer (2018, noviembre). Colombia Opina \# 2. Bogotá: Invamer S.A.S. Misión de Observación Electoral-MOE (2016). Medios de Comunicación y Plebiscito de refrendación de los acuerdos de paz. Bogotá: MOE.

Richard, E. y Saffon, S. (2015). "La paz en el visor mediático: el framing del noticiero sobre los diálogos de paz durante la campaña presidencial". Más poder local. Revista de comunicación política e institucional 27: 36-50.

Roseanu, J. (1997). “Cambio y complejidad. Desafíos para la comprensión en el campo de las relaciones internacionales". Análisis Político 32: 106-119.

Sánchez, M. (2017). “Medios y memoria: agenda informativa y diálogos de paz". Cuadernos Fronterizos 40: 14-16.

Sánchez, J.(2018). “La desmovilización de las FARC: ethos visual y rito de institucionalización". En Carlos Charry (ed.), Ciudadanías conectadas, sociedades en conflicto. Investigaciones sobre medios de comunicación, redes sociales y opinión pública. Bogotá: Universidad del Rosario.

Silva, G. (2005). "Para pensar critérios de noticiabilidade". Estudos em Jornalismo e Mídia, vol. II, no 1-1: 95-107. 
Snow, D. y Benford, R. (2000). "Framing Processes and Social Movements: An Overview and Assessment". Annual Review of Sociology, vol. 26: 611-639.

https://www.jstor.org/stable/223459?seq=1\#page scan tab contents

Snow, D. (2007). "Ideology, framing processes, and Islamic terrorist movements". Mobilization. An internationally Quarterly Review 12 (1): 119-136.

http://mobilizationjournal.org/doi/abs/10.17813/maiq.12.2.5717148 $\underline{712 w 21410}$

Traquina, N. (2018). “Teorias de Jornalismo”. En Porque as notícias são com são. Florianapolis: Editora Insular: 94-125.

Trussler, M, y Soroka, S. (2013). “Consumer Demand for Cynical and Negative News Frames". En Annual Conference of the Political Science Association. Victoria, BC: 28.

Van Dijk, T. (1990). La noticia como discurso. Barcelona: Paidós.

Van Dijk, T. (1997). Racismo y análisis crítico de los medios. Barcelona: Paidós.

Van Dijk, T. (2000). Ideología, una aproximación interdisciplinaria. Barcelona: Gedisa. 